\title{
Evaluation of the amount of residual lipid emulsion in chambers of flushed totally implantable venous access devices using fluorescence imaging
}

\author{
Naoya Okamura ${ }^{1}$ Takae Yamato ${ }^{1} \cdot$ Ippei Yamaoka $\mathbb{C}^{2}$
}

Received: 12 October 2018 / Revised: 26 April 2019 / Accepted: 17 May 2019 / Published online: 4 June 2019

(c) The Author(s) 2019. This article is published with open access

\begin{abstract}
The aim of the present study was to use a quantitative fluorescence imaging technique to evaluate the invisible amount of residual lipid emulsion in port chambers flushed with various fundamental protocols. Chambers were filled with lipid emulsion containing indocyanine green and then flushed with $5-70 \mathrm{~mL}$ of normal saline. Chambers were flushed at various speeds $(15-60 \mathrm{~mL} / \mathrm{min})$, with a time interval of 1 or $3 \mathrm{~s}$ between boluses, and with varying directions of flow. The slower the flushing speed, the more lipid emulsion that remained. Pulsatile flushing with either time interval did not decrease the residual amounts, and the areas well-cleansed after flushing were oriented to the bevel-opening direction. These findings suggest that to reduce the residual amount of lipid emulsion poured in a chamber, fast and furious flushing under continuous as opposed to pulsatile flushing is of paramount importance.
\end{abstract}

\section{Introduction}

Occlusion, a representative complication associated with totally implantable venous access devices (TIVADs), can lead to failure in successive infusions. Occlusions are occasionally caused by lipid aggregates, thrombus formation, or the precipitation of drugs or calcium salts $[1,2]$. Moreover, residual lipid emulsion in port chambers is a significant risk factor for catheter-related bloodstream infections because lipids have been identified as a microorganism growth factor [3].

Therefore after lipid infusion, the patency of the device necessitates appropriate flushing with saline. To perform appropriate flushing, the behavior of negligible residues in the device needs to be clarified. Hence, we evaluated the effectiveness of different flushing techniques for lipid emulsion in TIVAD port chambers using indocyanine green (ICG) fluorescence imaging.

Ippei Yamaoka

yamaokai@otsuka.jp

1 Information Center for Infusion Therapy and Product, Otsuka Pharmaceutical Factory, Inc., 115 Kuguhara, Tateiwa, Muya-cho,

\section{Materials and methods}

\section{Preparation for filling port chambers with lipid emulsion}

The lipid emulsion used in the present study consisted of Intralipos $^{\circledR}$ injection $20 \%$ (soybean oil $200 \mathrm{mg} / \mathrm{mL}$; Otsuka Pharmaceutical Factory, Inc., Tokushima, Japan) and ICG $\left(25 \mathrm{mg}\right.$ in $100 \mathrm{~mL}$ of Intralipos ${ }^{\circledR}$ injection $20 \%$, Diagnogreen ${ }^{\circledR}$ for injection $25 \mathrm{mg}$; Daiichi Sankyo Company, Ltd., Tokyo, Japan).

A 22-gauge Huber-point needle (Huber Plus ${ }^{\circledR}$ Noncoring Needle; C. R. Bard, Inc., Murray Hill, NJ, USA) was inserted into the central venous $(\mathrm{CV})$ port (X-Port isp ${ }^{\mathrm{TM}}$; C. R. Bard, Inc.) and the other end was connected to a closed connector (Bionector S; Vygon Japan Corp., Osaka, Japan). Finally, the prepared lipid emulsion was filled using a common infusion pump.

Naruto, Tokushima 772-8601, Japan

2 Medical Foods Research Institute, Otsuka Pharmaceutical Factory, Inc., 115 Kuguhara, Tateiwa, Muya-cho, Naruto, Tokushima 7728601, Japan 


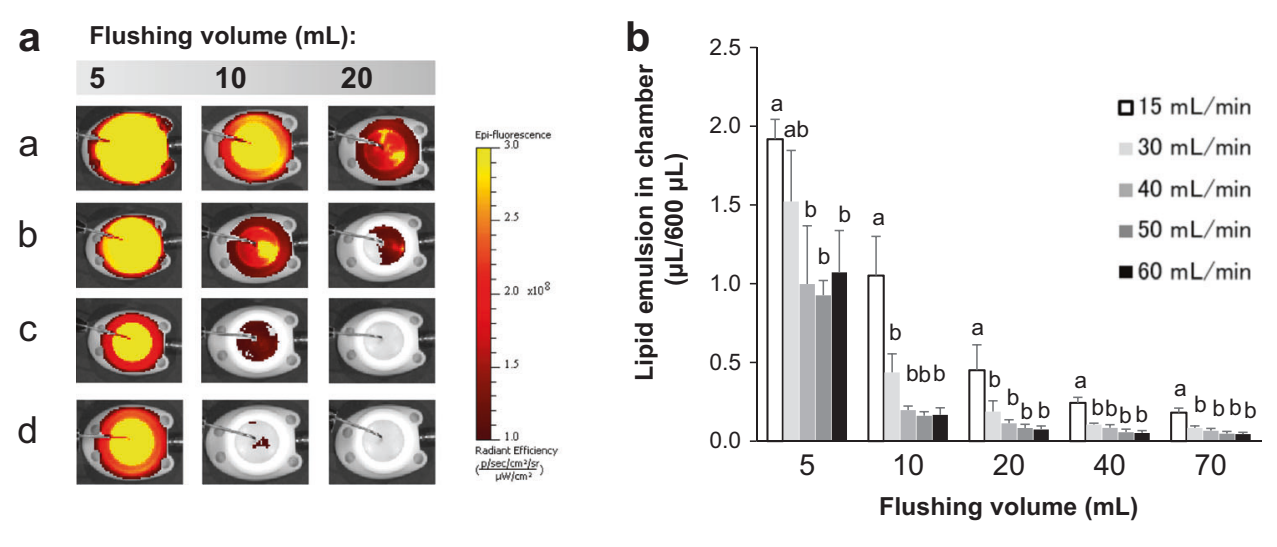

C Flushing volume $(\mathrm{mL})$ :

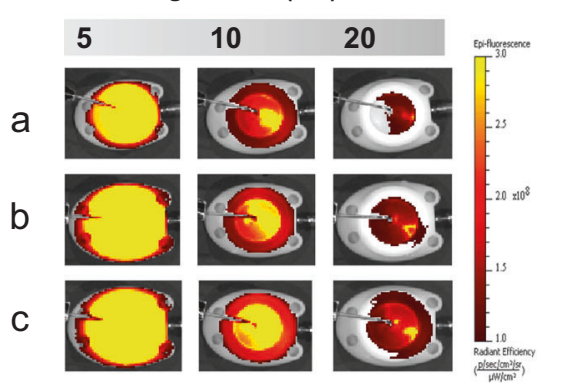

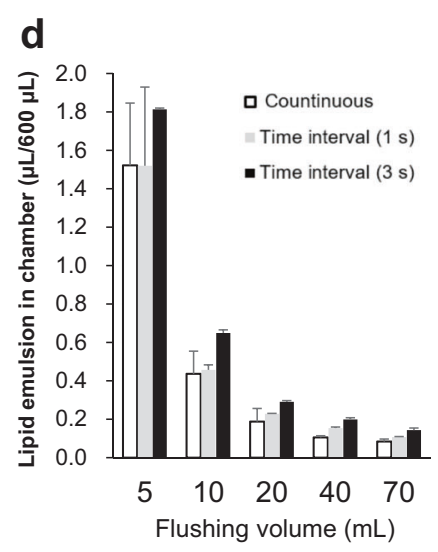

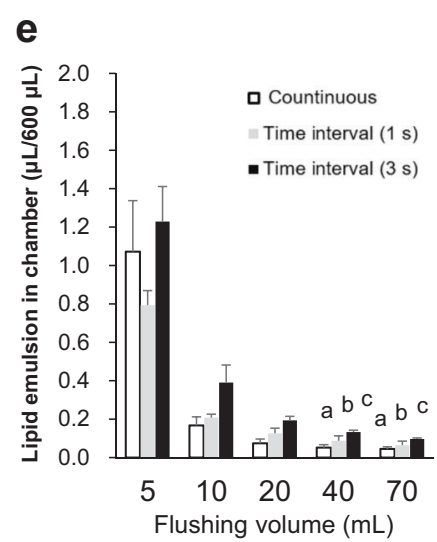

Fig. 1 Representative fluorescence images of residual lipid emulsion after continuous flushing at 15 (a), 30 (b), 40 (c), or 60 (d) $\mathrm{mL} / \mathrm{min}$ until reaching flushing volume (in a), and with or without (a) a time interval of $1 \mathrm{~s} \mathrm{(b)} \mathrm{or} 3 \mathrm{~s} \mathrm{(c)} \mathrm{between} \mathrm{boluses} \mathrm{at} 30 \mathrm{~mL} / \mathrm{min}$ (in c). The residual amounts at various speeds $(15-60 \mathrm{~mL} / \mathrm{min})$ until reaching flushing volume (in $\mathbf{b}$ ) and between continuous and pulse intermittent flushing at $30 \mathrm{~mL} / \mathrm{min}$ (in d) and $60 \mathrm{~mL} / \mathrm{min}$ (in e). Values are expressed as mean \pm standard deviation $(n=3)$. Different small letters indicate significant differences between groups $(p<0.05)$

(3) Effect of the hole orientation of the Huber needle: the needle was fixed in a central position and then placed so that the angle formed by the needle hole and the exit catheter was $0^{\circ}, 90^{\circ}$, or $180^{\circ}$.

These experiments were repeated three times under the same experimental conditions. The residual lipid emulsion in the chamber was calculated by monitoring the ICG using the IVIS Spectrum live imaging system (Perkin Elmer, Boston, MA, USA) [4].

\section{Statistical methods}

All values are presented as means \pm standard deviation. Differences between the treatments were analyzed using repeated-measures analysis of variance (ANOVA), followed by two-tailed Tukey's test when appropriate. The level of statistical significance was set at $p<0.05$. Ekuseru-Toukei 2015 statistical software (SSRI Co., Ltd., Tokyo, Japan) was used for all statistical analyses. 
Fig. 2 Representative brightfield and fluorescence images of chambers continuously flushed with $20 \mathrm{~mL}$ at 30 (a) or 60 (b) $\mathrm{mL} / \mathrm{min}$ at various insertion angles (in a). The residual amounts among various insertion angles after continuous flushing at 30 (in b) or 60 (in c) $\mathrm{mL} / \mathrm{min}$ in each volume with 5-70 mL. Values are expressed as mean \pm standard deviation $(n$ $=3$ ). Different small letters indicate significant differences between groups $(p<0.05)$ a
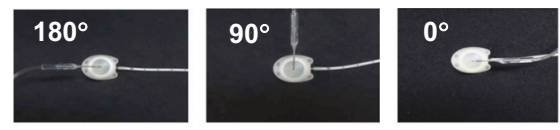

a
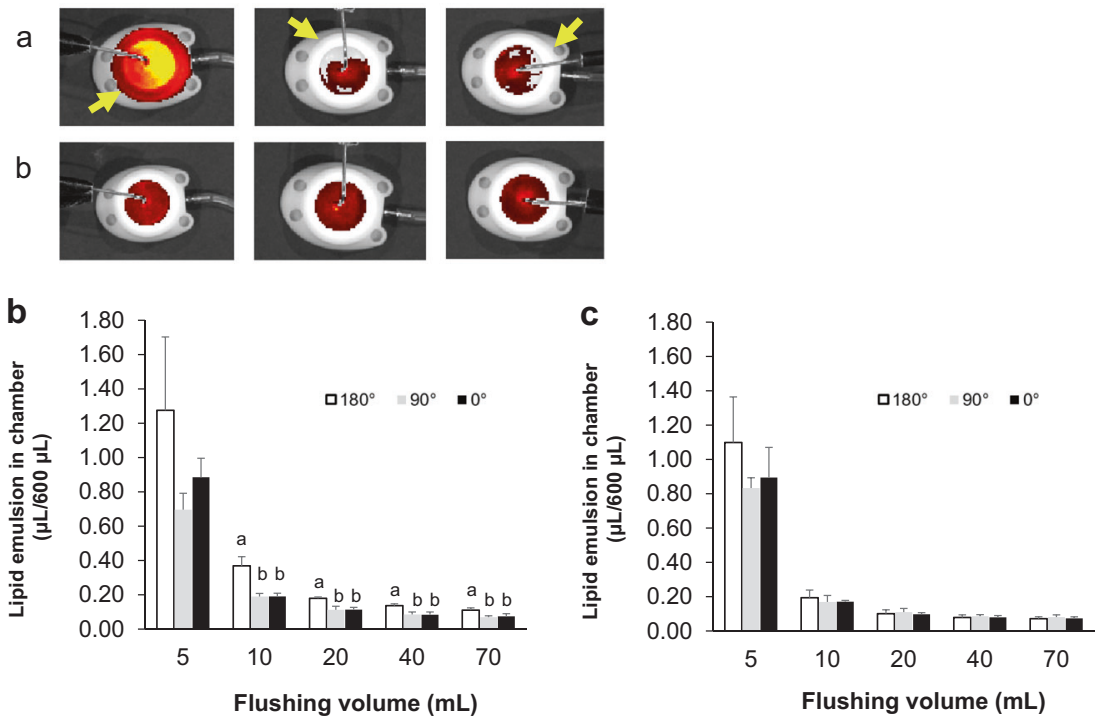

\section{Results}

Speeds at $<30 \mathrm{~mL} / \mathrm{min}$ left behind ICG fluorescence; by contrast, speeds at $>40 \mathrm{~mL} / \mathrm{min}$ did not (Fig. 1a). As shown in Fig. 1b, the higher the flushing speed, the lower the residual amounts of lipid emulsion $(p<0.05$; repeated-measures ANOVA). However, the residual amounts of lipid emulsion did not significantly differ when the flushing volume was increased to over $10 \mathrm{~mL}$ in the case of $>30 \mathrm{~mL} / \mathrm{min}$.

At a speed of $30 \mathrm{~mL} / \mathrm{min}$, the residual amounts after pulsatile flushing with a time interval of 1 or $3 \mathrm{~s}$ between boluses were not lower than those after continuous flushing (Fig. 1d). The pulsatile flushing left higher residual amounts with higher hold times at $60 \mathrm{~mL} / \mathrm{min}(3 \mathrm{~s}>1 \mathrm{~s}>0 \mathrm{~s} ; p<$ 0.05; repeated-measures ANOVA).

Figure $2 \mathrm{a}$ shows that the well-cleansed area corresponded to the hole orientation at a flushing speed of $30 \mathrm{~mL} / \mathrm{min}$, but when the flushing speed was $60 \mathrm{~mL} / \mathrm{min}$, the entire area was uniformly cleansed. When the hole orientation was opposite to the outlet catheter, more lipid emulsion remained compared with the other orientations examined (Fig. 2b)

\section{Discussion}

The present findings indicate that the faster the flushing speed and/or the higher the volume of normal saline, the lower the amount of residual lipid emulsion remaining in the chamber. If the flushing speed is slow, it cannot homogenously stir the lipid emulsion, resulting in a larger pool of lipid emulsion inside the chamber. By contrast, a comparably faster flushing speed could produce a turbulent flow inside the chamber, resulting in the adequate stirring of the lipid emulsion and a smaller pool of lipid emulsion inside the chamber. Flushing with $10-20 \mathrm{~mL}$ of normal saline using a CV catheter is recommended in clinical practice [1]. The results of the present study support this recommendation, but the flushing speed should exceed $40 \mathrm{~mL} / \mathrm{min}$.

Pulsatile flushing did not decrease the residual amounts of lipid emulsion compared with the continuous controls, and a longer time interval between the boluses reduced the cleansing performance in the case of higher flushing speeds. The interruption of turbulent flow by interval handling made it difficult to maintain turbulent flow in chambers, which resulted in a reduced cleansing effect. This result is supported by idea that the turbulent flow readily disappears if the flow continues to be blocked [5]. There may be differences in the cleansing efficacy between chambers with a wide space and catheters with a narrow lumen, as the effectiveness of pulsatile compared with continuous flushing has been demonstrated [6, 7].

The present findings may indicate that the direction of Huber-point needle bevel produces an area where lipid emulsion easily remains at slower flushing speeds. However, turbulent flow occurs in the chamber if the speed of the flushing flow is high; therefore, the lipid emulsion in the chamber might be cleansed evenly, regardless of the direction of the Huber-point needle bevel.

In conclusion, to reduce the residual amount of lipid emulsion in a chamber, fast and energetic continuous 
flushing, as opposed to pulsatile flushing, is of paramount importance.

Acknowledgements We wish to thank Dr. Yu Koyama for the advice and comments regarding this research. We are also grateful to Dr. Toru Takahashi for the hydrodynamic discussion and comments about our results. We would also like to acknowledge the dedicated efforts of Mr. Hiroshi Iwakiri, who was responsible for the field coordination and supervision of the study since its inception.

Author contributions NO, TY, and IY contributed equally to the conception of the study; NO and IY contributed to the study design; NO and TY contributed to the acquisition of data; and IY contributed to the statistical analysis. All authors contributed to the interpretation of the data and helped draft the manuscript. All authors are fully accountable for ensuring the integrity and accuracy of the work, and have read and approved the final manuscript for submission.

\section{Compliance with ethical standards}

Conflict of interest All the authors are employed by Otsuka Pharmaceutical Factory, Inc.

Publisher's note: Springer Nature remains neutral with regard to jurisdictional claims in published maps and institutional affiliations.

Open Access This article is licensed under a Creative Commons Attribution 4.0 International License, which permits use, sharing, adaptation, distribution and reproduction in any medium or format, as long as you give appropriate credit to the original author(s) and the source, provide a link to the Creative Commons license, and indicate if changes were made. The images or other third party material in this article are included in the article's Creative Commons license, unless indicated otherwise in a credit line to the material. If material is not included in the article's Creative Commons license and your intended use is not permitted by statutory regulation or exceeds the permitted use, you will need to obtain permission directly from the copyright holder. To view a copy of this license, visit http://creativecommons. org/licenses/by/4.0/.

\section{References}

1. Goossens GA. Flushing and locking of venous catheters: available evidence and evidence deficit. Nurs Res Pract. 2015;2015:985686.

2. Flaatten H, Klem W. Catheter occlusion, in which way are lipid emulsions responsible? JPEN J Parent Enter Nutr. 1988;12:320-1.

3. Kuwahara T, Kaneda S, Shimono K, Inoue Y. Effects of lipid emulsion and multivitamins on the growth of microorganisms in peripheral parenteral nutrition solutions. Int $\mathrm{J}$ Med Sci. 2013;10:1079-84.

4. Yamaoka I, Kagawa T, Mizugai K, Ebisu G. Detecting enteral nutrition residues and microorganism proliferation in feeding tubes via real-time imaging. Nutr Clin Pract. 2017;32:282-7.

5. Crowe C, Schwarzkopf J, Sommerfeld M, Tsuji Y. Chapter 3 size distribution. In: Multiphase flow with droplets and particles. Boca Ranton: CRC press; 1998.

6. Ferroni A, Gaudin F, Guiffant G, Flaud P, Durussel JJ, Descamps $\mathrm{P}$, et al. Pulsative flushing as a strategy to prevent bacterial colonization of vascular access devices. Med Devices (Auckl). 2014;7:379-83.

7. Guiffant G, Durussel JJ, Merckx J, Flaud P, Vigier JP, Mousset P. Flushing of intravascular access devices (IVADS)-efficacy of pulsed and continuous infusions. J Vasc Access. 2012;13:75-8. 